\title{
Assessment of Electrical Energy from Pyrolysis of Medical Waste in Jessore City, Bangladesh
}

\author{
Uday Som ${ }^{1}$, Md. Shameem Hossain ${ }^{2 *}$, Farzana Rahman ${ }^{3}$, Tithi Saha ${ }^{1}$, Md. Wasikur Rahman ${ }^{1}$ \\ ${ }^{1}$ Jessore University of Science and Technology, BANGLADESH \\ ${ }^{2}$ Khulna University of Engineering \& Technology, KUET, 9203 Khulna, BANGLADESH \\ 3 Jahangirnagar University, BANGLADESH
}

*Corresponding Author: shameemkuet@gmail.com

Citation: Som, U., Hossain, S., Rahman, F., Saha, T. and Rahman, W. (2019). Assessment of Electrical Energy from Pyrolysis of Medical Waste in Jessore City, Bangladesh. European Journal of Sustainable Development Research, 3(2), em0078. https://doi.org/10.20897/ejosdr/3965

Published: March 3, 2019

\begin{abstract}
Energy crisis and environmental degradation is considered most talked of the topics of modern global development. Medical waste has dangerous impacts on the environment. Besides, load shedding has come to be a great problem in socioeconomic development of Bangladesh for the reason that of the serious electricity crisis. This study also focused on energy recovery potentiality from plastic content of medical waste (PCMW) by converting it into electric energy. This plastic waste integrates an enormous amount of energy and consequently, attention in new renewable sources of energy from these wastes has been augmented, at the present time. Bangladesh as well as Jessore city faces an excessive environmental problem because of improper management of medical waste. This study demonstrated that the medical waste generation rate in Jessore city was found to be approximately 3 ton/day which is about $6.89 \%$ of total waste generation in this city throughout the study period. Besides, electric power generation projections from the PCMW were estimated at $74448 \mathrm{kWh}$ per year respectively. This study suggested that appropriate PCMW management policy as well as awareness increasing regarding the management of PCMW is requirement for the development of existing status of living condition.
\end{abstract}

Keywords: plastic content of medical waste (PCMW), pyrolysis process, medical waste management (MWM), electrical energy assessment

\section{INTRODUCTION}

Energy is an important figure for economic development and human being development for any country. Energy consumption has been increasing day by day in Bangladesh for the causes of rapid population growth and economic expansion. There is lack of energy in Bangladesh and these lacks of energy are disturbing tremendously to Bangladeshi economy because it has to depend on seriously on imports. It has been apparent that energy consumption appearances a dual way trending with economic growth, one is growth which depend on accessibility of environmental friendly and cost effective energy sources and where the another is rate of economic growth which is perceived to be dependent on demand of energy (Dash, 2012). The energy consumption combination was assessed as: indigenous natural gas $27.45 \%$, imported oil $11.89 \%$, imported coal $0.44 \%$, indigenous biomass $60 \%$ and hydro $0.23 \%$. Maximum population about $77 \%$ of the total population lives in rural regions but nearly $50 \%$ of them have not any land, most of them depend on conventional biomass fuels. In rural regions the availability of electricity is merely $22 \%$ whereas about $32 \%$ have no access to electricity. Merely $3-4 \%$ of the families depend on natural gas for cooking purposes. Merely around 2-3\% families depend on kerosene for cooking purpose and 
about $90 \%$ population use biomass for their cooking purposes (Islam et al., 2008). The energy, which helps to runs our household appliances that comes from fuel. The medical waste especially plastic content of medical waste (PCMW) can also be used as fuel (Hossain et al., 2017). Plastic materials contain a gradually increasing quantity of the industrial and municipal waste going into landfill. For the causes of enormous amount of plastic wastes that increases environmental pressures. There are found various types of plastics in medical waste such as syringes, Saline bag, pipettes, tube, plastics/polythene etc.

Recycling of plastics has come to be a leading subject in plastics industry. Medical wastes have threats to the environment and require specific management and treatment before its last disposal (Hassan et al., 2008). Also, recycling of the waste is another issue especially in wastewater treatment plant. Emerging technology such as MBR can reduce these wastes." (Sepehri et al., 2018).The innocuous dumping and treatment of medical wastes has been overlooked in Bangladesh. Medical waste is capable of triggering illnesses and disorder to people, if introduce to the environment it cause contaminating surface water, groundwater, soil and air (PRISM, 2005). For decreasing plastic waste, the technologies are advanced day by day, which are acceptable from the environmental opinion of view and are cost-effective. "Water supply also is another problem through the world especially due to the water scarcity. There are different emerging technologies such as MBR which can treat wastewater. Also, the waste sludge of this process can be used as a viable source of energy production. (Sepehri et al., 2018).Incineration and pyrolysis are generally engaged to acquire bio-fuel from plastic materials. Between these two methods, pyrolysis is one of the greatest effective and favorable techniques to acquire liquid fuel from PCMW (Howell, 1992). Pyrolysis is a thermal process which is operated in less or absence of oxygen. In this process, the biological elements of the decomposable elements produce liquid and gaseous products, which can be castoff as a source of energies and chemicals (Miskolczi et al., 2009). From this energy we can calculate or estimate electrical power. Very dissimilar experimental methods have been castoff to obtain energy from PCMW by thermal pyrolysis method. Various reactor structures have been established and used for example batch or semi batch (Hussain et al., 2012), spouted bed, fluidized bed, microwave, screw kiln and fixed bed (Lee and Shin, 2006). Batch, semi-batch and fixed bed reactors is popular because of its modest design and relaxed operation. In this study we use a batch type pyrolysis reactor to carry out the process. The purpose of this study is to discover alternate source of energy from PCMW through thermal pyrolysis method and estimates its electrical power.

\section{METHODOLOGY}

\section{Raw Materials}

Plastic medical waste used as raw material during the experiment, which was collected from various Clinic, hospital and diagnostic center of Jessore city, Bangladesh. After that these plastic materials were washed consecutively with water and $\mathrm{HCl}$ acid. These plastic were cut into small square shape different sizes for example $0.65 \mathrm{~cm}^{3}, 0.975 \mathrm{~cm}^{3}, 1.3 \mathrm{~cm}^{3}, 1.95 \mathrm{~cm}^{3}$. All plastic were cut cross-section wise of diverse sizes such as $1 \mathrm{~cm} \times 1 \mathrm{~cm}$ $\times 0.65 \mathrm{~cm}=0.65 \mathrm{~cm}^{3}, 1 \mathrm{~cm} \times 1.50 \mathrm{~cm} \times 0.65 \mathrm{~cm}=0.975 \mathrm{~cm}^{3}, 2 \mathrm{~cm} \times 1 \mathrm{~cm} \times 0.65 \mathrm{~cm}=1.3 \mathrm{~cm}^{3}$ and $2 \mathrm{~cm} \times 1.5$ $\mathrm{cm} \times 0.65 \mathrm{~cm}=1.95 \mathrm{~cm}^{3}$. These chopped plastics were used as feed material for the thermal pyrolysis process.

\section{Experimental Procedure}

Pyrolysis of PCMW was directed by a batch type fixed-bed reactor. The design of the experimental set-up can be presented in Figure 1. The device used in the pyrolysis of PCMW contained of batch reactor completed of 14 $\mathrm{cm}$ inside diameter and $28 \mathrm{~cm}$ outside diameter and carbon steel of $8 \mathrm{~cm}$ length. A k-type thermocouple with digital temperature recorder associated to the reactor was used to estimate inside heat of the reactor. This process was directed for variety of feed size and temperature. The PCMW are shredded into four different sizes which are fed to the reactor. The heat, need for the pyrolysis, supplied by the heater. The heat is supplied in continuous basis and vapour forms in the reactor. Before beginning the trial, the reactor was expunged by flowing $\mathrm{N}_{2}$ gas for 5 min to eliminate air inside. The condensable pyrolytic liquid products or wax were collected through the condenser and weighed. At the vent of reactor, a condenser was devoted to condense the vapours coming out of it. These condensed vapours are collected in a vessel as the liquid product where there is specific quantity of noncondensable vapours which are just left out inside the reactor was weighed. After pyrolysis, the solid residue left out inside the reactor was weighed. Then the weight of gaseous product was calculated from the material balance. Reactions were carried out at different temperatures rang-ing from 80 to $300{ }^{\circ} \mathrm{C}$. The schematic diagram of fixed bed pyrolysis plant is shown in Figure 1. 


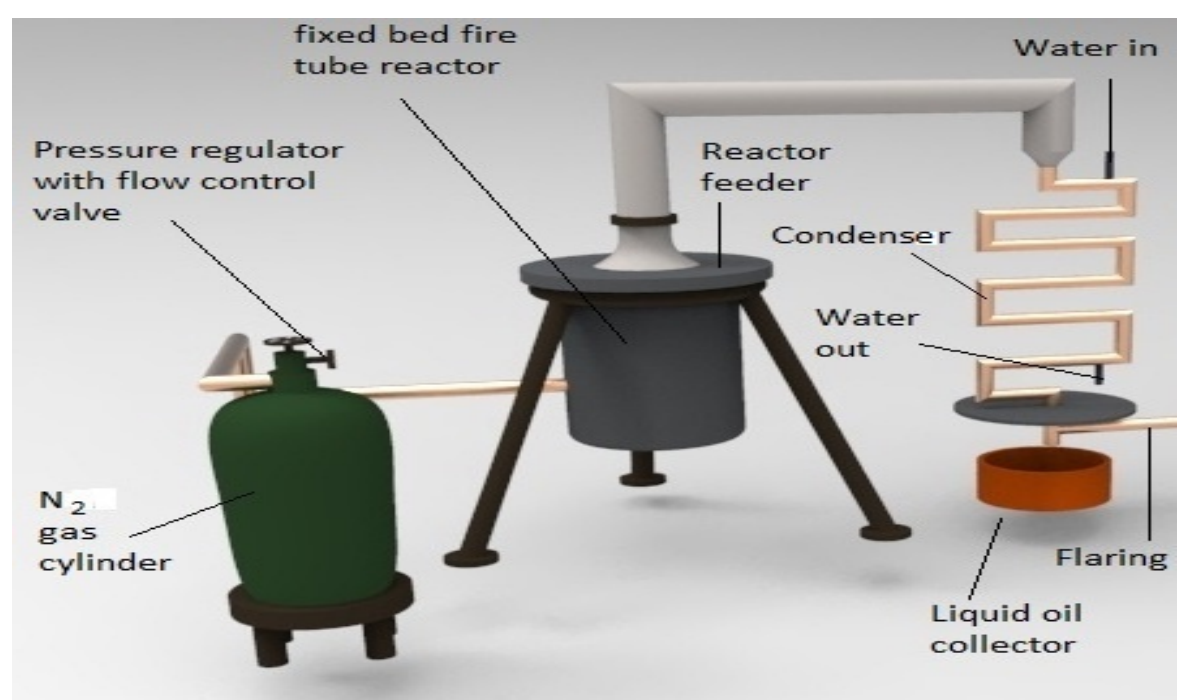

Figure 1. Schematic diagram of fixed bed pyrolysis plant (Hossain et al., 2017)

\section{RESULT AND DISCUSSON}

\section{Elemental and Proximate Analysis of PCWM}

Elemental and proximate analysis PCMW is very important to determine numerous properties of PCMW. The heating rate and volatile constituents are the vital factors for PCMW pyrolysis. The Elemental and proximate analyses of PCMW with higher calorific rate are showed in below Table 1.

Table 1. Proximate and elemental analysis PCMW

\begin{tabular}{lclclc}
\hline Proximate analysis (wt \%) & Elemental analysis (wt \%) & & \multicolumn{2}{l}{ Reference waste syringe sample (Dash, 2012) } \\
\hline Moisture & 0.82 & Carbon $(\mathrm{C})$ & 72.56 & Carbon $(\mathrm{C})$ & 72.2 \\
\hline Volatile & 62.7 & Hydrogen $(\mathrm{H})$ & 11.17 & Hydrogen $(\mathrm{H})$ & 11.46 \\
\hline Fixed carbon & 32.31 & Nitrogen $(\mathrm{N})$ & 5.82 & Nitrogen $(\mathrm{N})$ & 0.18 \\
\hline Ash & 4.17 & Sulphur $(\mathrm{S})$ & 0.227 & Sulphur $(\mathrm{S})$ & 0.03 \\
\hline H.C.V $(\mathrm{MJ} / \mathrm{kg})$ & 33.3 & Others & 10.22 & Oxygen $(\mathrm{O})$ & 16.13 \\
\hline
\end{tabular}

\section{TG Analysis}

The TG plots originate at heating rates of $10^{\circ} \mathrm{C}$ per min for the samples of PCMW are presented in Figure 2. It illustrations the alterations of fractional mass-loss (TG curves) with respect to pyrolysis response temperature $\mathrm{T}$ for $10^{\circ} \mathrm{C}$ per min heating rates for PCMW. The reaction zones change to the upper temperature states and the peak elevations escalation with the increase of heating rate.

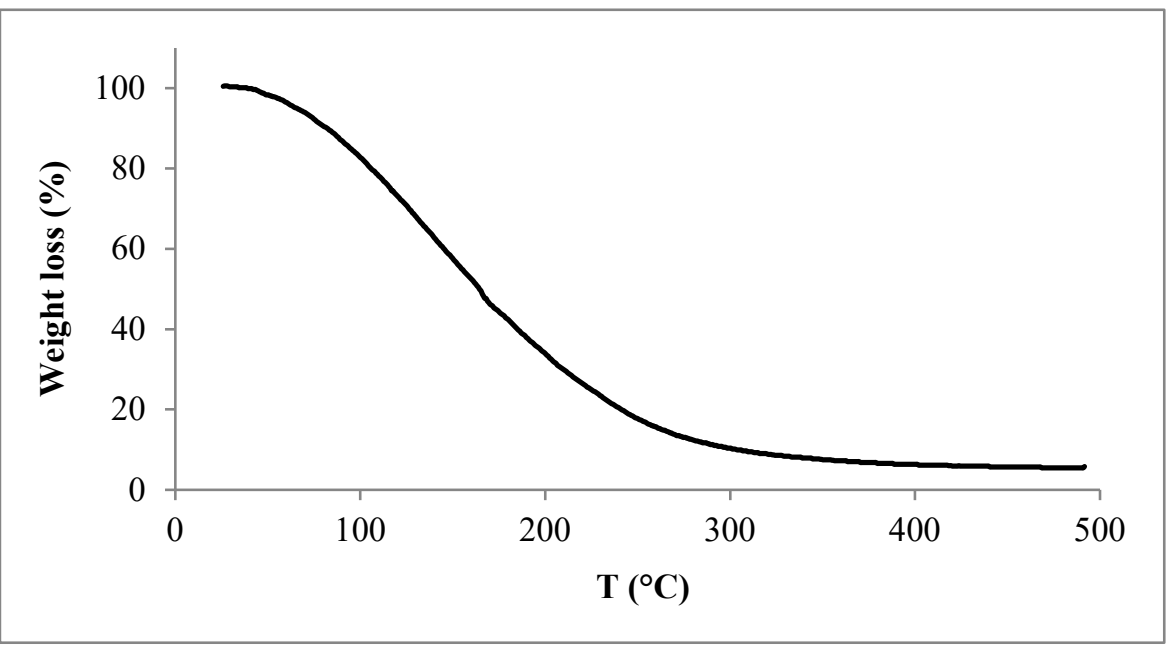

Figure 2. TG analysis curve 


\section{Effect of Temperature on Pyrolytic Yield}

Pyrolysis of PCMW in batch type fixed-bed reactor, the experimentations was directed in the temperature range of 80 to $300^{\circ} \mathrm{C}$. The investigations were directed to detect the significance of pyrolysis temperature on yield.

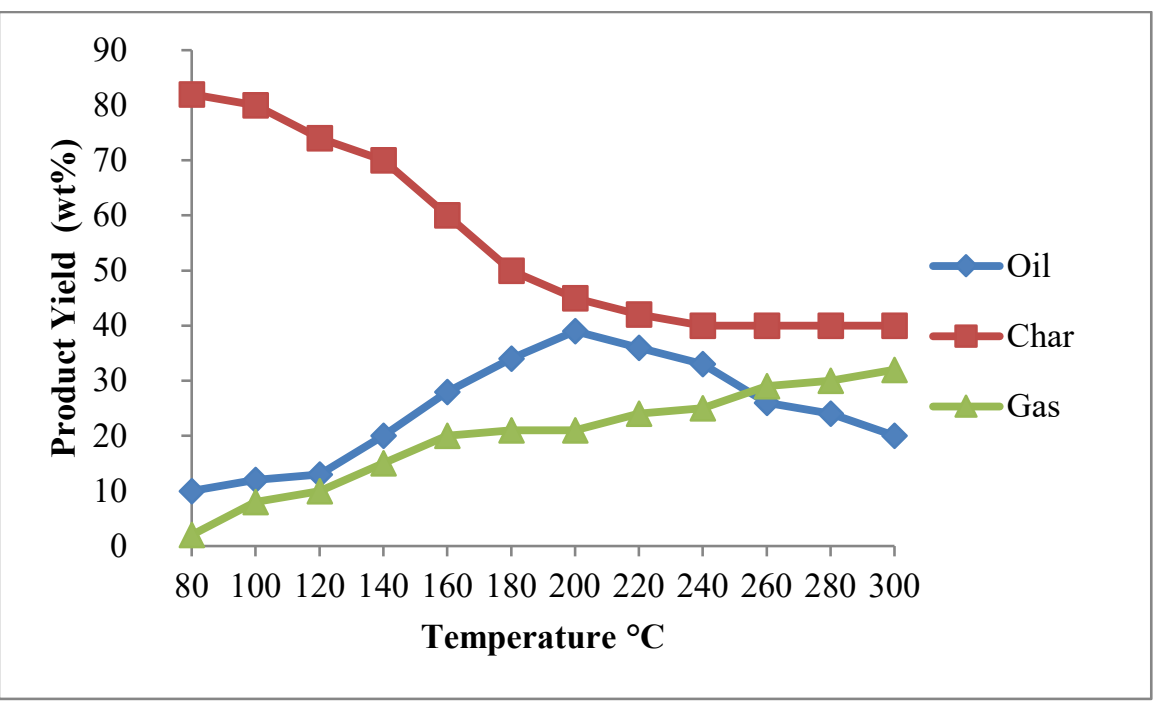

Figure 3. Effect of temperature on pyrolytic yields for plastic based medical waste of feedstock size $0.65 \mathrm{~cm}^{3}$

At diverse temperature of numerous feedstock sizes $\left(0.65,0.975,1.30\right.$, and $\left.1.95 \mathrm{~cm}^{3}\right)$, there were achieved three types of pyrolysis yields such as liquid oil, solid and gas are presented in Figure 3 for feedstock $(1 \mathrm{~cm}$ $\times 1 \mathrm{~cm} \times 0.65 \mathrm{~cm}$ ) due to straightforwardness. It is stated from the figure that when the escalation of temperature occur, the rate of liquid manufacture augmented up until it attained a maximum value and formerly reduced. All the data denote alike nature. Among the 4 sample sizes, the excellent result was attained for the feed size of 0.65 $\mathrm{cm}^{3}$. When the temperature augmented from 80 to $20{ }^{\circ} \mathrm{C}$, the production of liquid augmented first from $10 \mathrm{wt} . \%$ to a maximum value of $39 \mathrm{wt} . \%$ and then reduces to $20 \mathrm{wt} . \%$ at a temperature of $300^{\circ} \mathrm{C}$. The gas production augmented from 2 to $21 \mathrm{wt.} \% \%$ over the entire temperature range, whereas char yield declined from 88 to $40 \mathrm{wt}$. $\%$, formerly remain residues were almost constant. It is pragmatic that a properly sharp optimum occurs in temperature at which supreme production of liquid was attained possibly because of strong cracking of plastic at $200^{\circ} \mathrm{C}$ temperature. The gas manufacture augmented over the whole temperature range to a uppermost value of $40 \mathrm{wt} . \%$ at $300^{\circ} \mathrm{C}$, whereas, char yield decayed up to $220^{\circ} \mathrm{C}$ and formerly remained just about constant.

\section{Comparison in Properties of Pyrolytic Liquid to Some Other Commercial Fuel}

To assess the properties of pyrolytic liquid are very important for practical solicitations. The properties of pyrolytic liquid are much closer to commercial fuel like diesel and furnace oil that can be used as a great source of energy. The viscosity $(4.0 \mathrm{cSt})$ of pyrolytic oil is a little higher than diesel fuel $(2.8 \mathrm{cSt})$ and lower than furnace oil $(6.2 \mathrm{cSt})$. The density and higher calorific value of the prepared oil are comparable to supplementary fuels (Demiral and Ayan, 2011). Pyrolysis oil is much closer to commercial fuel so, it can be used as a great alternative source of liquid fuel or energy. The comparison of fuel properties of pyrolytic oil with some other commercial fuels are presented in Table 2.

Table 2. Comparison of fuel properties of pyrolytic oil with some other commercial fuels

\begin{tabular}{|c|c|c|c|c|}
\hline Fuel properties & $\begin{array}{l}\text { Density } \\
\left(\mathrm{kg} / \mathrm{m}^{3}\right)\end{array}$ & $\begin{array}{c}\text { Gross calorific Value } \\
(\mathrm{MJ} / \mathrm{kg})\end{array}$ & $\begin{array}{c}\text { Flash point } \\
\left({ }^{\circ} \mathrm{C}\right)\end{array}$ & References \\
\hline Pyrolytic oil & 840 & 41.32 & 39 & Present work \\
\hline Waste syringe pyrolysis oil from & 829 & 42.54 & -6 & (Dash, 2012) \\
\hline Gasoline & $720-780$ & $42-46$ & -43 & (Sakata et al., 1999) \\
\hline Diesel & $820-850$ & $42-45$ & $53-80$ & (Jamradloedluk and Lertsatitthanakorn, 2014) \\
\hline Bio-diesel & 880 & $37-40$ & $100-170$ & (Jamradloedluk and Lertsatitthanakorn, 2014) \\
\hline Heavy fuel oil & $940-980$ & 40 & $90-180$ & (Roy, 1992) \\
\hline Kerosene & 780 to 810 & $43.1-46.2$ & $37-65$ & (Petroleum Product Surveys, 1986) \\
\hline
\end{tabular}




\section{Assessment of Electrical Energy from Produce Liquid Oil}

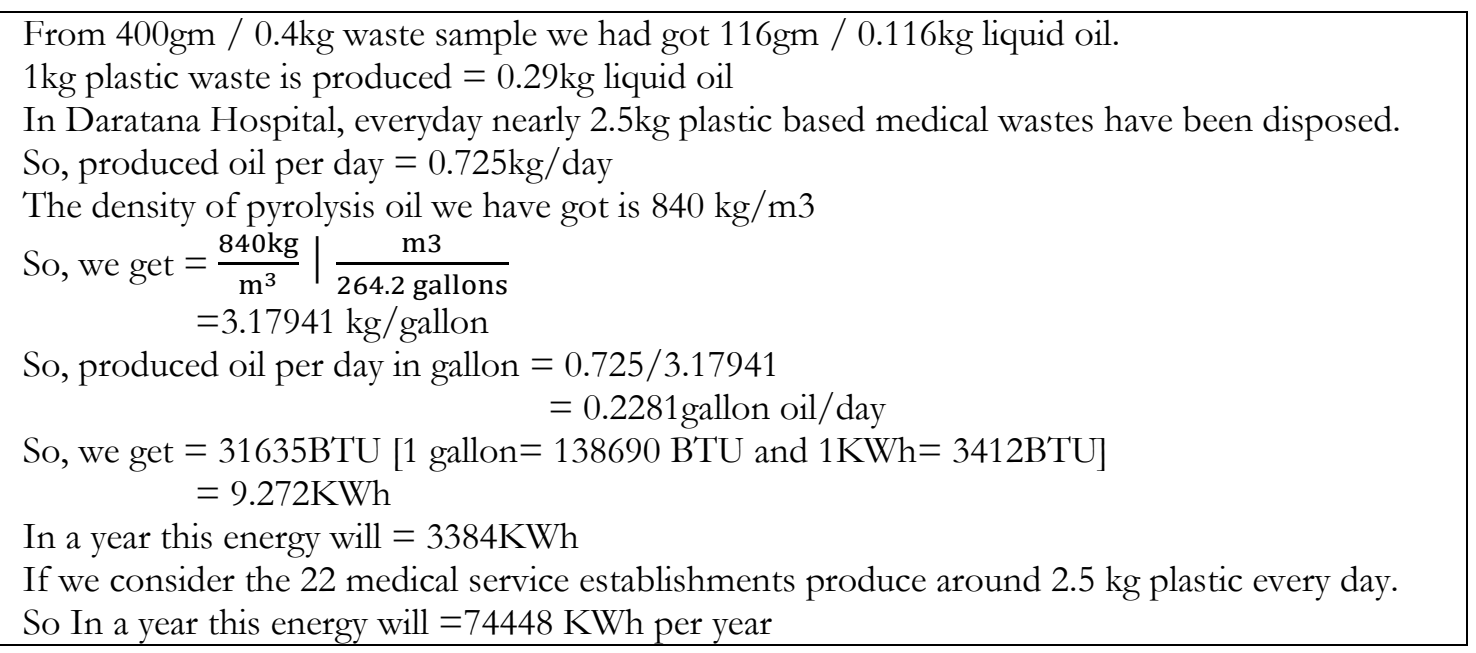

Note: - when medical waste convert into electrical energy then minimum $70 \%$ of energy lost as heat and other mechanical losses as utilized by electrical generator. So, 30\% energy gets from the liquid oil. If researcher can use this vast amount of medical waste then it could be converted into electrical energy. There are many hospitals in our country. Researcher can produce an alternative energy source from this medical waste. The source of energy can met demand of our national electricity problem. So, writer has emphasis on this for the fulfillment the demand of energy.

\section{CONCLUSION}

Handling of medical waste is a challenging mission and also a mandatory feature for standard living. Recovery of electrical energy from PCMW by thermal pyrolysis was explored in the present issue quite effectively that added value to the energy sector. Around 22 medical service establishments produce huge quantity of plastic waste in Jessore city. Waste to Energy solves the difficulties of PCMW disposal while recovering the energy from this material with the important benefits of environmental superiority. The physical properties of pyrolystic oil attained were in the range of other commercial/ transportation and moderate quality fuels. It has been presented that a simple batch pyrolysis method can transform medical waste to valuable chemical products with animportant yield which differs with temperature. The electrical power generation prospects from the PCMW were estimated at $74448 \mathrm{KWh}$ per year respectively. A counseling meeting should be detained with healthcare service providers, environmentalist, municipal authorities and waste handlers to choice suitable place and technology of manufacturing energy from PCMW.

\section{NOMENCLATURE}

$\begin{array}{ll}\mathrm{PCMW} & \text { Plastic content of medical waste } \\ \mathrm{HCl} & \text { Hydrochloric acid }\end{array}$

\section{REFERENCES}

Demiral, İ. and Ayan, E. A. (2011). Pyrolysis of grape bagasse: effect of pyrolysis conditions on the product yields and characterization of the liquid product. Bio resource technology, 102(4), 3946-3951. https://doi.org/10.1016/j.biortech.2010.11.077

Dash, A. (2012). Study on the thermal pyrolysis of medical waste (plastic syringe) for the production of useful liquid fuels. Doctoral dissertation.

Hassan, M. M., Ahmed, S. A., Rahman, K. A. and Biswas, T. K. (2008). Pattern of medical waste management: existing scenario in Dhaka City, Bangladesh. BMC Public Health, 8(1), 36. https://doi.org/10.1186/1471-24588-36

Hossain, M. S., Som, U., Hossain, J., WasikurRahman, M. and Iqbal, S. A. (2017). Recovery of Alternative Fuel from Thermal Pyrolysis of Medical Wastes. In Proceedings of the 4th the International Conference on Engineering Research, Innovation and Education (ICERIE 2017), 13-15 January, SUST, Sylhet, Bangladesh, 683-688. 
Hossain, M. S., Islam, M. A., Rahman, A. N. M. M. and Kader, M. G. (2017). Alternative Fuel from Pyrolysis of Waste Motorcycle Tire. Proceedings of the 4thInternational Conference on Engineering Research, Innovation and Education, Sylhet, Bangladesh, 897-901.

Howell, S. G. (1992). A ten year review of plastics recycling. Journal of hazardous materials, 29(2), 143-164. https://doi.org/10.1016/0304-3894(92)85066-A

Hussain, Z., Khan, K. M., Perveen, S., Hussain, K. and Voelter, W. (2012). The conversion of waste polystyrene into useful hydrocarbons by microwave-metal interaction pyrolysis. Fuel processing technology, 94(1), 145-150. https://doi.org/10.1016/j.fuproc.2011.10.009

Islam, M. R., Tushar, M. S. H. K. and Haniu, H. (2008). Production of liquid fuels and chemicals from pyrolysis of Bangladeshi bicycle/rickshaw tire wastes. Journal of Analytical and Applied Pyrolysis, 82(1), 96-109. https://doi.org/10.1016/j.jaap.2008.02.005

Jamradloedluk, J. and Lertsatitthanakorn, C. (2014). Characterization and utilization of char derived from fast pyrolysis of plastic wastes. Procedia Engineering, 69, 1437-1442. https://doi.org/10.1016/j.proeng.2014.03.139

Lee, K. H. and Shin, D. H. (2006). A comparative study of liquid product on non-catalytic and catalytic degradation of waste plastics using spent FCC catalyst. Korean Journal of Chemical Engineering, 23(2), 209-215. https://doi.org/10.1007/BF02705718

Miskolczi, N., Angyal, A., Bartha, L. and Valkai, I. (2009). Fuels by pyrolysis of waste plastics from agricultural and packaging sectors in a pilot scale reactor. Fuel Processing Technology, 90(7), 1032-1040. https://doi.org/10.1016/j.fuproc.2009.04.019

Petroleum Product Surveys, Motor Gasoline. (1986). National Institute for Petroleum and Energy Research. Winter 1986/1987.

PRISM Bangladesh. (2005). Survey Report on Hospital Waste Management in Dhaka City. Unpublished Report Dhaka.

Roy, C., Chaala, A. and Darmstadt, H. (1999). The vacuum pyrolysis of used tires: End-uses for oil and carbon black products. Journal of Analytical and Applied Pyrolysis, 51(1), 201-221. https://doi.org/10.1016/S01652370(99)00017-0

Sakata, Y., Uddin, M. A. and Muto, A. (1999). Degradation of polyethylene and polypropylene into fuel oil by using solid acid and non-acid catalysts. Journal of Analytical and Applied Pyrolysis, 51(1), 135-155. https://doi.org/10.1016/S0165-2370(99)00013-3

Sepehri, A. and Sarrafzadeh, M. H. (2018). Effect of nitrifiers community on fouling mitigation and nitrification efficiency in a membrane bioreactor. Chemical Engineering and Processing-Process Intensification, 128, 10-18. https://doi.org/10.1016/j.cep.2018.04.006 